\title{
Nanotopological-Tailored Calcium Phosphate Cements for the Odontogenic Stimulation of Human Dental Pulp Stem Cells through Integrin Signaling
}

\author{
So-Youn Lee ${ }^{1, \#}$, Hyung-Mun Yun ${ }^{1,2, \#}$, Roman A. Perez ${ }^{3,4,5}$, Sara Gallinetti ${ }^{5}$, Maria-Pau Ginebra ${ }^{5}$, \\ Seong-Jun Choi ${ }^{3,4}$, Eun-Cheol Kim ${ }^{1, *}$, Hae-Won Kim ${ }^{3,4,6^{*}}$ \\ ${ }^{1}$ Department of Oral and Maxillofacial Pathology, and Research Center for Tooth and Periodontal Regeneration \\ (MRC), School of Dentistry, Kyung Hee University, Seoul, Republic of Korea. \\ ${ }^{2}$ Department of Preventive and Society Dentistry, School of Dentistry, Kyung Hee University, Seoul, Republic of \\ Korea. \\ ${ }^{3}$ Institute of Tissue Regeneration Engineering (ITREN), Dankook University, Cheonan, Republic of Korea \\ ${ }^{4}$ Department of Nanobiomedical Science \& BK21 PLUS NBM Global Research Center for Regenerative Medicine, \\ Dankook University, Cheonan, Republic of Korea \\ ${ }^{5}$ Biomaterials, Biomechanics and Tissue Engineering Group, Department of Materials Science and Metallurgy, \\ Technical University of Catalonia (UPC), Avda. Diagonal 647, E-08028 Barcelona, Spain. \\ ${ }^{6}$ Department of Biomaterials Science, College of Dentistry, Dankook University, Cheonan, Republic of Korea
}

\footnotetext{
\# SY Lee and HM Yun contributed equally to this work as first authors.

* Corresponding authors:

Hae-Won Kim, PhD, Professor, Institute of Tissue Regeneration Engineering (ITREN), Dankook University, Cheonan 330-714, Republic of Korea, Tel) +82 41550 3081; Fax) +82 41550 3085; E-mail) kimhw@dku.edu Eun-Cheol Kim, D.D.S., Ph.D. , Professor, Dept. of Maxillofacial Tissue Regeneration, School of Dentistry, Kyung Hee University, 1 Heogi-dong, Dongdaemun-gu, Seoul, 130-701, Republic of Korea, Tel) +82-2-961-0746; Fax) +82-2- 960-1457; E-mail) eckim@khu.ac.kr
}

For: RSC Advances 


\section{ABSTRACT}

Calcium phosphate cements (CPCs) are the unique class of inorganic injectables attractive for the repair and regeneration of hard tissues. Tailoring the crystallite properties of CPC, particularly to represent nanotopological feature, is favorable for stimulating biological reactions. Nanotopological tailoring has recently been achieved on CPCs by simply modulating the sizes of the initial particles. Herein, we aim to investigate the effects of nanotopological-tailored CPCs on the odontogenic differentiation of stem cells derived from human dental pulp (HDPSCs) as well as on their implicated signal pathways. The initial adhesion of the cells was substantially higher on the nano-CPCs than on the micro-CPCs. A series of indications of odontogenesis, including alkaline phosphatase activity and gene expressions (dentin matrix protein-1, dentin sialophosphoprotein, osteocalcin, ostepontin, and bone sialoprotein) were significantly stimulated on the nano-CPC in comparison to the micro-CPC. Furthermore, the integrin downstream pathways of the cells, including FAK, paxillin, Akt, MAPK, and NF-KB, were highly activated on the nano-CPC with respect to those on the micro-CPCs. Collectively, the nanotopological CPCs significantly enhance the odontogenic differentiation of HDPSCs when compared to conventional micro-CPCs through the integrin-associated signaling pathways, which implies that the nanotopological CPCs maybe more potent in the repair and regeneration of dentinpulp complex tissues.

Keywords; Nanotopological surface; Calcium phosphate cements; Human dental pulp stem cells; Odontogenic differentiation; Integrin signal pathway. 


\section{Introduction}

The regeneration of dental pulp-dentin tissues ultimately targets preserving teeth via endodontic approaches. Dental pulp tissue engineering requires a triad of dental pulp stem cells (DPSCs), morphogens (including growth factors and cytokines), and scaffolds. ${ }^{1}$ The successful regeneration of dental pulp requires the DPSCs to differentiate adequately, secreting extracellular matrix molecules in dental-pulp tissues such as dentin sialoprotein (DSP), dentin phosphoprotein (DPP), dentin matrix protein (DMP-1), osteocalcin (OCN), osteopontin (OPN), and bone sialoprotein (BSP). ${ }^{2,3}$

Calcium phosphate cements (CPCs) are well-known bioactive synthetic bone graft materials. ${ }^{4}$ They can form in an aqueous environment to hydroxyapatite, a mineral phase of bone and dentin., CPCs thus exhibit excellent biocompatibility, osteoconductivity, and sealing ability, and provide new options for dental treatments as a filler/sealer for root canal treatment. ${ }^{7,8}$ In addition, the self-setting and the moderate compressive strength even in loading conditions suggests that CPCs are superior to pure calcium hydroxides; which means that CPCs may have applications in inducing reparative dentin formation in pulp capping or as a lining material. ${ }^{9}$ Previously, we reported that CPCs and the composites with biopolymers facilitated growth and differentiation of human DPSCs. ${ }^{10}$ In addition, we demonstrated that newly developed calcium phosphate-based sealers (CAPSEAL I and II) showed higher cell viability and lower inflammatory mediators in periodontal ligament cells when compared to other sealers, showing the potential of these new materials to promote bone regeneration. ${ }^{11}$ However, the slow degradation rate with limited hard tissue ingrowth has also been suggested that needs improvement in those cementation materials. ${ }^{12,13}$

The properties of the CPCs, including their calcium deficient hydroxyapatite (CDHA) crystalline microstructure, porosity and pore size and specific surface area, are dependent on the characteristics of the initial CPC powders and can determine the adsorption rate and the release kinetics of proteins. ${ }^{14}$ Previous studies have shown that the variation in the particle size (micro or nano) of the powders allows the CPCs to develop highly distinct microstructures, either plate-like or needle-like structure. ${ }^{15,16}$ The compressive strength of the CPCs after hardening increases as the surface area increases, which suggests that a harder CPC was derived from the smaller particle size of the raw materials. ${ }^{17}$ Therefore, the particle size is the key factor that determines the final properties of the 
CPCs, especially by affecting the kinetics of the chemical reaction and the mechanical consolidation of the cements. The reduction in the particle size has been reported to produce a substantial decrease in the setting time and to accelerate the hardening of the CPCs. ${ }^{18}$ Furthermore, the different topography of the substrates has been shown to significantly affect the behavior of osteoblast-like cells, showing a slight decrease in the proliferation rate but with substantially improved differentiation activity. ${ }^{15,19}$

However, the role that the particle size plays with respect to the underlying cement compositions, particularly in the odontogenic differentiation, and its relevant signal transduction mechanisms remain unclear. To elucidate this, here we developed two different-sized CPC particles, namely nano-sized and micro-sized CPC, and the effects of the different particle size on the odontogenic potential and the underlying signal pathway mechanisms in human dental pulp stem cells (HDPSCs) were investigated.

\section{Materials and methods}

\subsection{Preparation of nano- and micro-sized CPC powders and settings}

The CPC powder phase was composed of $\alpha-T C P$, which was obtained from the mixture of calcium hydrogen phosphate $\left(\mathrm{CaHPO}_{4} ;\right.$ Sigma-Aldrich $\left.\mathrm{C} 7263\right)$ and calcium carbonate $\left(\mathrm{CaCO}_{3} ;\right.$ Sigma-Aldrich C4830), after heat-treatment at $1400^{\circ} \mathrm{C}$ for $15 \mathrm{~h}$ (Hobersal CNR-58), followed by quenching. The $\alpha-$ TCP was milled in a Pulverisette 6 planetary ball mill (Fritsch GmbB) following two different protocols, as previously described, ${ }^{19}$ to obtain for the starting powders of the CPC in the form of nano-CPC (CPC-N) and micro-CPC (CPC-M) samples, which have nano-sized and micro-sized particle size distributions, respectively. The particle size distribution was analyzed by laser diffraction (LS 13320 Beckman Coulter), dispersing the particles in ethanol in an ultrasonic bath to avoid aggregation. The characteristics of the two different micro/nanoparticles are described in Table 1 according to the initial properties. 2 wt \% precipitated hydroxyapatite (PHA; Alco ref. 1.02143) was added as a seed. The liquid phase was composed of an accelerant solution $\left(2.5 \% \mathrm{Na}_{2} \mathrm{HPO}_{4}\right)$, and the powder and the liquid were mixed at an L/P ratio of $0.65(\mathrm{ml} / \mathrm{g})$. The mixture was introduced into Teflon disk moulds with diameters of $15 \mathrm{~mm}$ and a height of $2 \mathrm{~mm}$. The CPC disks were then left to set in a Ringers solution at $37^{\circ} \mathrm{C}$ for 7 days to obtain a complete transformation of the $\alpha$-TCP into CDHA. The samples were 
finally sterilized by ethanol immersion for 1 hour. The samples were then placed in 24 well plates and were washed 3 times with PBS to remove any remaining ethanol. The samples were then left overnight in the presence of culture media in order to completely wet the pores as well as the surface of the CPCs.

\subsection{Characterization of CPCs}

Mercury intrusion porosimetry (MIP; Autopore IV Micromeritics) was carried in order to examine the porosity content (open porosity) and to determine the pore size distribution within the hardened CPC. The specific surface area of the CPC was measured via $\mathrm{N}_{2}$ adsorption according to the BET method (ASAP 2020; Micromeritics). The crystalline phases were assessed via X-ray diffraction (XRD; Philips MRD). Ni-filtered Cu Ka radiation was used and the step-scanning was performed with an integration time of $50 \mathrm{~s}$ at intervals of $0.017^{\circ} 2 \theta$. The peaks were indexed by means of the JCPDS cards $29-359$ for $\alpha-$ TCP and 9-432 for HA. The relative amounts of the different phases that were present in the samples after 7 days in water were estimated on the basis of the peak intensity variation by means of the external standard method, with a pure $\alpha-$ TCP as the external standard.

\subsection{Cell culture}

The immortalized HDPSCs were transfected with a telomerase catalytic subunit of a human telomerase reverse transcriptase (hTERT), ${ }^{20}$ kindly provided by Professor Takashi Takata (Hiroshima University, Japan). The cells were cultured in a-MEM supplemented with $10 \%$ FBS, $100 \mathrm{U} / \mathrm{ml}$ penicillin, and $100 \mu \mathrm{g} / \mathrm{ml}$ streptomycin in a humidified atmosphere of $5 \% \mathrm{CO}_{2}$ at $37{ }^{\circ} \mathrm{C}$. In order to induce differentiation, the cells were cultured in an osteogenic medium (OM; $50 \mu \mathrm{g} / \mathrm{mL}$ ascorbic acid, $10 \mathrm{mM}$ $\beta$-glycerophosphate, and $100 \mathrm{nM}$ dexamethasone) as previously described ${ }^{21-24}$. The culture medium was exchanged every 2 days, and upon confluence, the cells were detached with a minimum amount of trypsin-EDTA (Gibco) that was inactivated with FBS after $5 \mathrm{~min}$. The cells were then either recultured or used for further experiments.

A direct cell culture method was performed on the CPC to assess the effect that micro or nano CPCs had in the presence of odontogenic media. To this end, $3 \times 10^{5}$ HDPSCs were seeded on 
each sample. As a control, the same number of cells was cultured at the bottom of the 24 well plates which was maintained in normal proliferation media as well as osteogenic media.

\subsection{MTT assay}

The cell viability was determined by a 3-(4, 5-dimethylthiazolyl-2-yl)-2, 5-diphenyltetrazolium bromide (MTT). The MTT is based on a WST-1 reaction that produces a purple formazan dye in an amount that is directly related to the number of viable cells. After 3, 7 and 14 days, the medium was removed and replaced with $200 \mu \mathrm{l}$ of serum-free medium followed by an addition of $20 \mu \mathrm{l}$ of MTT solution. The reagent was left to react for $4 \mathrm{~h}$ and then the reactant was read at an absorbance of $450 \mathrm{~nm}$. A minimum of four replicates were assayed for each condition.

\subsection{Cell morphology by fluorescence microscopy}

The morphology of the cells was further observed via fluorescence microscopy (Cell Voyager, Yokogawa, Japan). After $60 \mathrm{~min}$, the cells were fixed with 4\% paraformaldehyde solution and were incubated first with mouse monoclonal anti-human p65 antibody (Santa Cruz Biotechnology, Santa Cruz, CA) and then with fluorescein isothiocyanate (FITC)-conjugated goat anti-mouse IgG (Invitrogen life technology, Grand Island, NY). The cells were then counter-stained for nuclei with 10 $\mu \mathrm{g} / \mathrm{mL}$ of propidium iodide.

\subsection{Cell adhesion assay}

The cells were seeded in nano-CPC or micro-CPC and were then cultured for $1,2,4$, and $8 \mathrm{~h}$. The adhesion was determined by using a CytoSelect Cell Adhesion Assay Kit (Cell Biolabs, San Diego, CA). Briefly, after $30 \mathrm{~min}$ of incubation at $37^{\circ} \mathrm{C}$, the adherent cells were fixed, stained and colorimetrically quantified in a plate reader at $560 \mathrm{~nm}$. The percentage was calculated by comparing the absorbance of each material to that of negative control.

\subsection{ALP activity assay}

As a marker of early osteoblast differentiation, alkaline phosphatase (ALP) activity was assessed in 24-well plates after 14 days of incubation in media supplemented with OM and CPC. The cells were then washed with PBS, and then the cell layers were scraped into a solution containing $20 \mathrm{mM}$ Tris- 
$\mathrm{HCl}, \mathrm{pH}$ 8.0, and $150 \mathrm{mM} \mathrm{NaCl}, 1 \%$ Triton X-100, 0.02\% NaN3, $1 \mu \mathrm{g} / \mathrm{mL}$ aprotinin. The lysates were homogenized. Then, the ALP activity was assayed via spectrophotometric measurements $(410 \mathrm{~nm}$, Beckman Coulter, Fullerton, CA) of p-nitrophenol release at $37^{\circ} \mathrm{C}$. In order to normalize protein expression to total cellular protein, a fraction of the lysate solution was used in a Bradford protein assay $(n=4)$.

\subsection{Semi-quantitative reverse transcriptase-polymerase chain reaction (RT-PCR)}

The total RNA of the pulp cells was extracted using a TRIzol reagent (Life Technologies, Gaithersburg, MD) according to the manufacturer's instructions, and $1 \mu \mathrm{g}$ RNA was reverse-transcribed for the firststrand cDNA synthesis (Gibco BRL, Rockville, MD). The cDNA was amplified in $20 \mu \mathrm{L}$ with $2.5 \mathrm{mM}$ of magnesium dichloride, 1.25 units of Ex Taq polymerase (Bioneer, Daejeon, Korea) and $1 \mu \mathrm{M}$ of specific primers. Amplification took place for 30 cycles in a DNA thermal cycler, and the primer sequences for the differentiation markers are summarized in Table 1. The PCR products were resolved on a $1.5 \%$ agarose gel and were stained with ethidium bromide.

\subsection{Western blot analysis}

The cells $\left(3 \times 10^{5}\right)$ were cultured to $70 \%$ confluence in a 6 -well plate and were treated for the indicated times under OS or CPC. The cells from each set of the experiments were harvested and were washed twice in cold tris-buffered saline. The cells were solubilized in ice-cold $1 \%$ Triton X-100 lysis buffer. After $30 \mathrm{~min}$ on ice, the lysates were clarified by centrifugation. The proteins $(20 \mu \mathrm{g})$ were resolved via SDS-PAGE (10\% acrylamide) and were transferred to nitrocellulose membranes, and were probed with specific Abs (diluted 1/1,000), followed by incubation with secondary horseradish peroxidase-conjugated $A b(1 / 100,000)$. The proteins were detected by enhanced chemiluminescence system (Amersham, Piscataway, NJ) according to the manufacturer's instructions and exposed to Xray.

\subsection{Statistical analysis}

The differences among the groups were analyzed using a one-way analysis of variance combined with the Bonferroni test. All of the values were expressed as mean \pm standard deviation, and the differences were considered significant at $p<0.05$. 


\section{Results}

\subsection{Initial particles used for the nano- and micro-CPCs}

Table 2 summarizes the characteristics of the initial particles used for the nano- and micro-CPCs. While the initial particle size for the micro-CPCs was $5.84 \mu \mathrm{m}$ that for the nano-CPCs was $2.44 \mu \mathrm{m}$. Furthermore, the specific surface area of the micro-CPC particles was $1.23 \mathrm{~m}^{2} / \mathrm{g}$, and that of the nano-CPC particles was $3.05 \mathrm{~m}^{2} / \mathrm{g}$.

\subsection{Physico-chemical properties of nano- and micro-CPCs}

When the CPC particles were hardened with liquid, the phase of the CPCs was examined by XRD, as shown in Fig. 1. A complete transformation of the initial $\alpha$-TCP into HA was observed during the 7 days of reaction in an aqueous solution. The crystalline morphologies of the hardened nano- and micro-CPCs were observed by SEM after a complete transformation into HA, as shown in Fig. 2. While a large-sized plate-like morphology could be seen for the micro-CPCs, a much smaller-sized (far less than $1 \mu \mathrm{m}$ ) needle-like shape was obtained for the nano-CPCs, revealing the significant influence of the initial particle size had on the crystalline nano-/micro-morphology of cements.

Fig. 3 shows the pore size distribution of the micro- and nano-CPCs. The micro-CPCs presented a higher pore population in the micrometric range $(1.20 \mu \mathrm{m})$ while the nano-CPCs tended to have fewer micrometric pores and higher nanometric pores (lower than $1 \mu \mathrm{m}$ ). Despite the considerable differences in the pore size, the porosities were shown to be identical with a value of $54 \%$. The specific surface area also showed a considerable difference, with a value of $18.98 \mathrm{~m}^{2} / \mathrm{g}$ for the micro-CPCs and a value of $39.05 \mathrm{~m}^{2} / \mathrm{g}$ for the nano-CPCs.

\subsection{Effects on the cell adhesion and proliferation}

The HDPSCs were cultured either with control medium or with odontogenic medium (OM) on the culture dish or on the CPCs. The cell adhesion rate was measured for up to $8 \mathrm{~h}$ (Fig. 4A). Cell adhesion appeared to be higher on the CPC-N than on the CPC-M at all culture periods, but a statistical significant difference was only noticed at 4 and $8 \mathrm{~h}$. The cells adhered initially actively spread and grew on all sample groups. The cell viability was then evaluated up to 14 days, by means of an MTT assay. Data are presented as a percentage to the culture dish without OM. When the cells 
were cultured without OM, both CPC groups showed slightly lower cell viability primarily during the initial period. When cultured with $\mathrm{OM}$, the cell proliferation significantly improved, which was also clearly shown in the CPC-cultured cells. The results showed that both CPC groups substantially supported the growth of the HDPSCs for up to 14 days, with fairly comparable levels at that period to those of culture dish culture.

\subsection{Effects on odontogenic differentiation}

The effects of the nano-/micro-topologies of CPCs on the odontogenic differentiation of HDPSCs were assessed by the ALP activity and the mRNA levels of odontogenic genes. Figure 5A shows the ALP activity of the HDPSCs after culture for 7 and 14 days. Without OM, both CPC groups showed a substantial increase in the ALP activity during both periods. When cultured under the OM conditions, the increase in the ALP activity was more considerable. Of note, the CPC-N showed significantly higher levels than the CPC-M for both culture periods. The gene expression related to odontogenesis (e.g. DMP-1, DSPP, OCN, OPM, and BSP) was observed at 7 and 14 days of culture (Fig. 5B). The RT-PCR band intensity was much higher under the OM conditions (vs. without OM) for the groups. Furthermore, the band intensity of the CPC-N was much higher than that of the CPC-M, particularly with OM at both periods.

\subsection{Signal transduction pathways}

In order to determine the signaling pathways involved in the odontogenesis of HDPSCs by the topological-tailored CPCs, the integrins and the intracellular adhesion molecules in the downstream pathways were analyzed in terms of gene and protein expressions, respectively. The mRNA levels of the integrin subsets, including $\alpha 1, \alpha 2$, and $\beta 1$ were upregulated via nano- and micro- CPC in a timedependent manner relative to the CPC-free culture dish (Fig. 6A). However, there was a significant difference between CPC-N and CPC-M for both periods. The integrin downstream signaling proteins in phosphorylated form, including p-FAK, p-paxillin, and p-Akt, were further analyzed by Western blot (Fig. 6B). Results showed significantly enhanced values, particularly p-FAK and p-Akt, in the CPC-N than in the CPC-M,

Since the integrin downstream signal pathway is involved in the activation of the mitogenactivated protein kinases (MAPK) and of the nuclear factor- $\mathrm{KB}(\mathrm{NF}-\mathrm{KB}){ }^{25}$, we next examined whether 
the nano- or the micro-CPC treatment affected the protein expressions of the MAPKs and NF-KB. The phosphorylation of p38, c-Jun N-terminal kinase (JNK) and the extracellular signal-related kinase (ERK) was higher on CPC-N than on CPC-M (Fig. 7A). As shown in Fig. 7B, the CPC-N induced substantial level of phosphorylation and degradation in the $\mathrm{I} \mathrm{KB} \alpha$ as well as in the nuclear translocation of p65 (NF-KB). In a similar manner, the confocal images showed that NF-kB p65 in the nucleus markedly increased by CPC-N than by CPC-M.

\section{Discussion}

In this study, we have examined whether the initial particle size of the CPCs had any beneficial effects on the odontogenic potential of HDPSCs. Because HDPSCs are potential cell source for the applications in endodontic regeneration, they are considered to provide a promising assessment tool for the odontogenic differentiation effects of the biomaterials developed. ${ }^{26,27}$

Our study indicated that the nano-/micro-topological parameter of the CPCs did not show any confirmative effects on the cell growth of HDPSCs although the initial cell adhesion events were stimulated on the nano-CPCs than on the micro-CPCs. In fact, some previous works on the behavior of osteoblastic cells cultured on similar CPC groups showed the cells had slightly lower proliferation levels on the nano-CPCs. ${ }^{15,19,28}$ It was suggested that the osteoblastic cell growth might be reduced on the nano-CPC due to the tight adhesion binding of cells to the underlying matrix, which consequently led to limited cell spreading and mitosis. ${ }^{15}$ Slightly different from that observation, here the nano-CPCs appeared not to delay the cell proliferation behaviors of the HDPSCs with respect to the micro-CPCs. The difference in cell type (osteosarcoma-derived cells vs. human dental pulp stem cells) and thus the different cellular adaptation to underlying substrate conditions may be a possible reason, which however, needs more clarification in future studies.

Rather than on the cell proliferation, the effects of the nano-sized CPCs were more clearly demonstrated on the odontogenic differentiation. The results of the ALP activity and the expression of marker genes such as BSP, OPN, OCN, DSPP, and DMP-1 indicated that nano-CPCs substantially promoted odontogenic differentiation when compared to micro-CPCs. ALP is mainly expressed on the cellular membrane of the osteoblasts and odontoblasts and is used as an important marker for the early differentiation cascade. ${ }^{29}$ Furthermore, DSPP and DMP-1 have been used as the odontogenic specific markers of HDPSCs while the OCN, OPN, and BSP genes are also expressed in osteogenic 
process. ${ }^{30}$ Therefore, analyses of these markers can inform whether the HDPSCs are sufficient committed to an odontoblastic lineage.

The RT-PCR band intensities, when quantified, gave significant improvement in those series of odontogenic genes by the nano-CPCs, and this was more noticeable at the prolonged culture period of 14 days. It is considered that the HDPSCs exposed to the underlying CPC matrices for such a long period are considered to experience microenvironments quite different from those when simply cultured on tissue culture plastic. The nanotopological physical factor of CPCs should drive the stem cells to better conform to an odontogenic lineage with the proper supply of biochemical cues (OM medium). In addition to this topological physical factor, the chemical factor of possible ionic release is also considered to get involved in the odontogenic stimulation of HDPSCs. In fact, both CPC groups, even without the OM medium, led to substantial level of odontogenic differentiation and this was more noticeable at the prolonged culture period (14 days), when the ionic releases from CPCs would possibly be more pronounced. Although here we could not examine the ionic releases from CPCs, it is deduced that the nano-CPCs can release the ions at higher levels than the micro-CPCs due to the higher surface area since the ionic dissolution of calcium phosphates is surface reaction-controlled and thus surface area-dependent.

The integrin signaling pathway plays an important role in the cell-matrix interactions that control cell adhesion, survival, proliferation, and differentiation. ${ }^{31}$ The $\alpha_{1} \beta_{1}$ and $\alpha_{2} \beta_{1}$ integrins are the major adhesive molecule-binding receptors in cells that form bone and dentin, where $\alpha_{1} \beta_{1}$ having a higher affinity for the basement membrane type IV collagen while $\alpha_{2} \beta_{1}$ for the fibrillar type I collagen. ${ }^{32}$ Herein, the integrin subunits $\alpha_{1}, \alpha_{2}$, and $\beta_{1}$ were shown to be expressed substantially in HDPSCs at the very early time points on both nano- and micro-CPCs, and the expression levels were significantly higher when cultured on nano-CPCs than on micro-CPCs, implicating the HDPSCs recognized the nanotopological substrate much better than the microtopological one through the matrix receptors.

The downstream signaling of integrins may involve the activation of intracellular protein kinases, such as the focal adhesion kinase (FAK), paxillin, and Akt. $^{33}$ In particular, the phosphorylation of FAK, paxillin and Akt was also shown to steadily increase in line with the integrin expressions. From a quantification, the HDPSCs on nano-CPCs expressed higher levels of $p$-FAK and p-Akt whilst lower levels of p-paxillin. It is unclear yet that the reason for the different stimulations between the intracellular down-streaming signals; it is postulated that other adhesion complex molecules that are 
regulated by the FAK might be involved more heavily than the paxillin, and regarding this more indepth profiling of different sets of adhesion molecules will be needed. In fact, multiple integrin signaling pathways may interact through a variety of mechanisms, from membrane-proximal clustering of the two integrin types to the activation of a common downstream signaling pathways, ${ }^{34}$ thus the current data for the integrin-dependent yet non-harmonized FAK/paxillin/Akt activation by nano-CPCs also suggest the complex mechanistic events might contribute to signal enhancements in the nano-CPC-treated HDPSCs.

The downstream signaling of the intracellular molecules, mainly FAK, may involve the activation of MAPK and NF-KB. ${ }^{25}$ Our study demonstrated that the phosphorylation of MAPK and the activation of NF-KB were higher when cultured on nano-CPC than on micro-CPCs. These results indicate that the nano-CPCs might act through the FAK, Akt, MAPK pathways to induce NF-KB activation in the HDPSCs. The results are also consistent with previous studies on the bioceramic scaffolds or mineralized biopolymer scaffolds that promoted matrix-dependent differentiation of human osteoblasts through the MAPK signaling pathway ${ }^{34}$ and the activation of FAK, Akt, MAPK, and NF$\mathrm{KB} .{ }^{26}$ One consideration in the activation of NF- $\mathrm{KB}$ is that the NF- $\mathrm{KB}$ is involved in various signaling processes, not only in the osteogenic differentiation of mesenchymal stem cells ${ }^{35-37}$, but also in the osteoclastic stimulation via RANK-RANKL signaling ${ }^{38}$. In other words, the final results of NF-KB signaling in cells depend on what upstream factors activate it. Therefore, the ultimate activation of NF$\mathrm{KB}$ should be understood in this context of positive as well as possible adverse facet, and the osteoclastic responses to the nano-CPCs may be a future interesting area of research. Within the limited findings, we could at least correlate the integrin-mediated adhesion signaling with the odontogenesis of HDPSCs, which was substantially stimulated on the nanotopological-tailored CPCs.

\section{Conclusions}

This is the first study that investigates the molecular signaling pathways through which nano-sized CPCs exert a substantial odontogenic stimulation of the HDPSCs. Our results demonstrate that nanosized CPCs are superior to micro-sized CPCs in terms of their odontogenic differentiation in the HDPSCs through FAK, Akt, MAPK, and NF-KB signaling pathways. The results imply that the importance of particle size (particularly nano-sized particles) of cements that ultimately find usefulness as stem cell matrices and defect fillers for the endodontic repair and regeneration. 


\section{Acknowledgements}

This work was supported by grants from the National Research Foundation of Korea (NRF) funded by the Korean government (MSIP) (No. 2012R1A5A2051384 \& No. 2009-0093829). 


\section{Figure Legends}

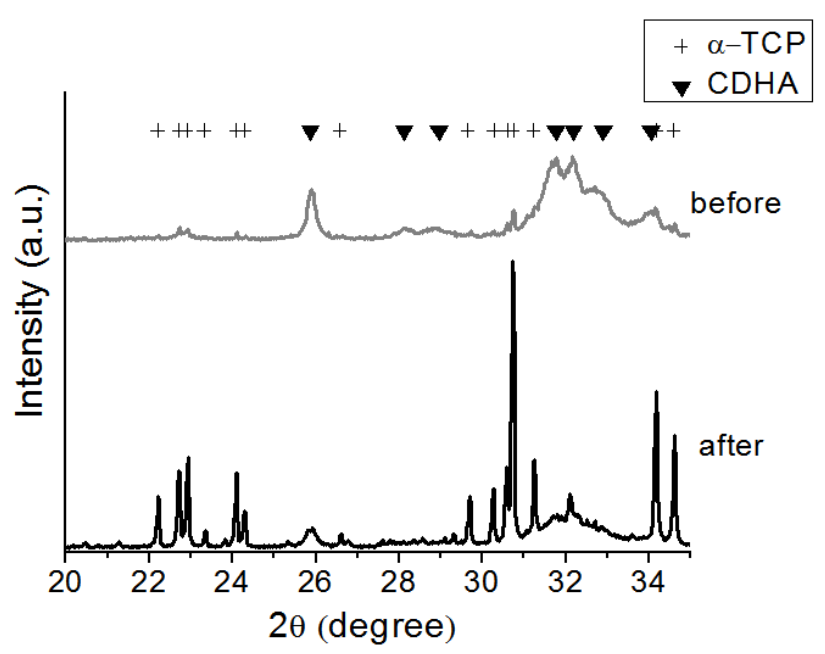

Figure 1. XRD patterns of the CPC powders, showing initial alpha-TCP phase that transformed completely to calcium-deficient hydroxyapatite (CDHA) after immersion for 7 days. 


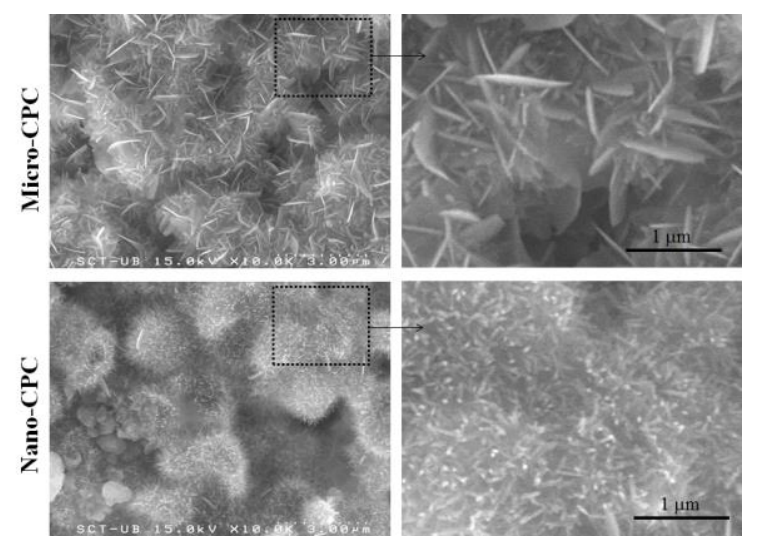

Figure 2. SEM images of micro- and nano-CPC at different magnifications. 


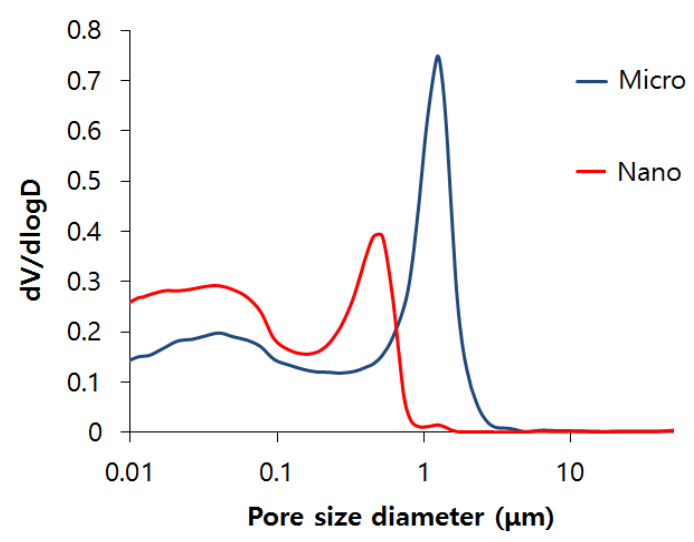

Figure 3. Characterization of pore size distribution of hardened CPC samples, showing nano-sized pores in the nano-CPC and micro-sized pores in the micro-CPC. 

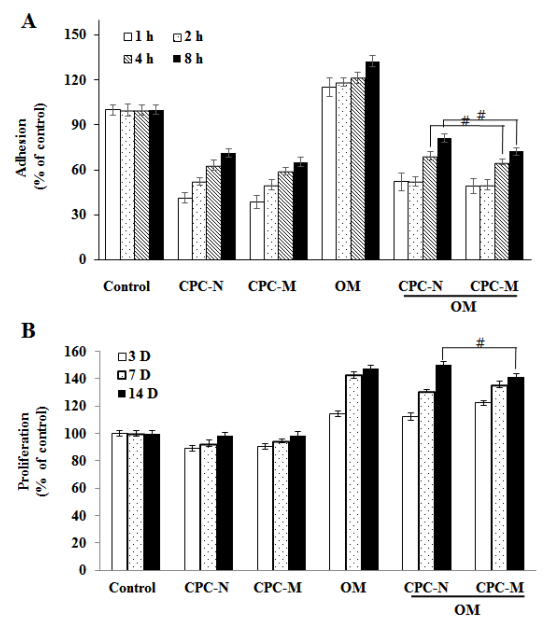

Figure 4. Effects of the nano- and micro-CPCs on the proliferation and adhesion in HDPSCs. The cells were cultured in CPC with or without osteogenic medium (OM) containing $50 \mu \mathrm{g} / \mathrm{mL}$ ascorbic, 10 $\mathrm{mM} \beta$-glycerophosphate, and $100 \mathrm{nM}$ dexamethasone for 7 and 14 days. (A) Cell growth and (B) adhesion determined with an MTT assay. \#: statistically significant difference compared between the groups $(p<0.05)$. 


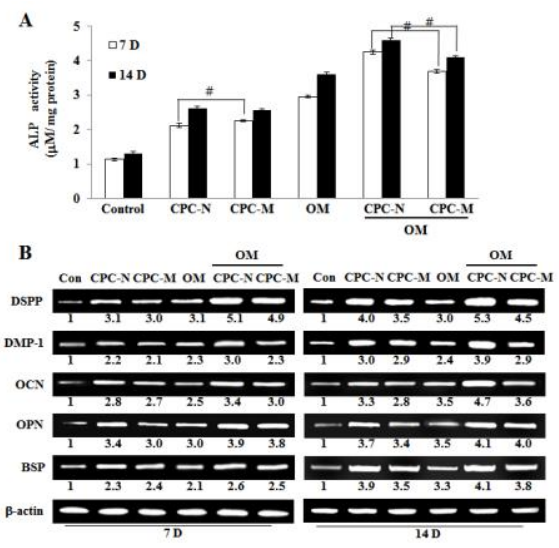

Figure 5. Odontogenic differentiation of HDPSCs; (A) ALP activity, \#: statistically significant difference compared between the groups $(p<0.05)$, and $(B)$ gene expressions. The band intensity of each gene was normalized to that of corresponding $\beta$-actin, and then to that of control group, as numbered below the band. 


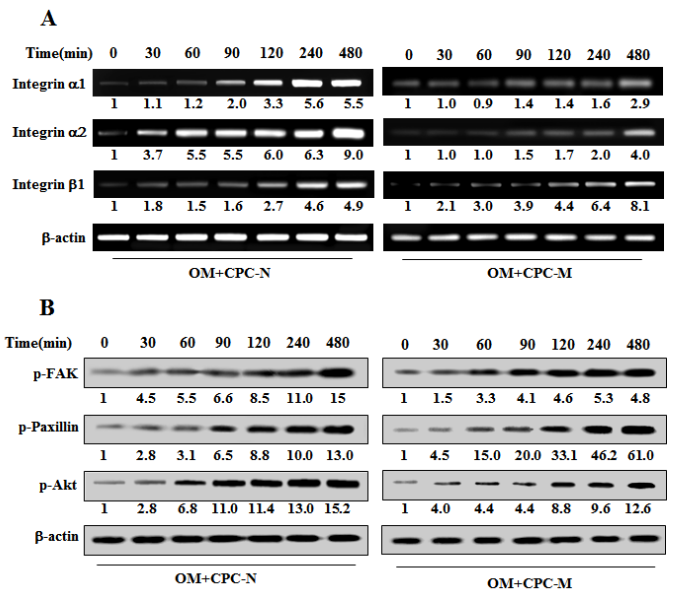

Figure 6. Effects of the nano- and micro-CPC on the expression of integrin (A) and its downstream pathways (B) in HDPSCs. Cells were cultured in CPCs with or without osteogenic medium (OM) for the indicated times. The mRNA (A) and protein expressions (B) were determined via RT-PCR and Western blot analysis, respectively. The band intensity of each gene or protein at each time point was normalized to that of the corresponding $\beta$-actin, and then to that at time 0 , as numbered below the band. 
A

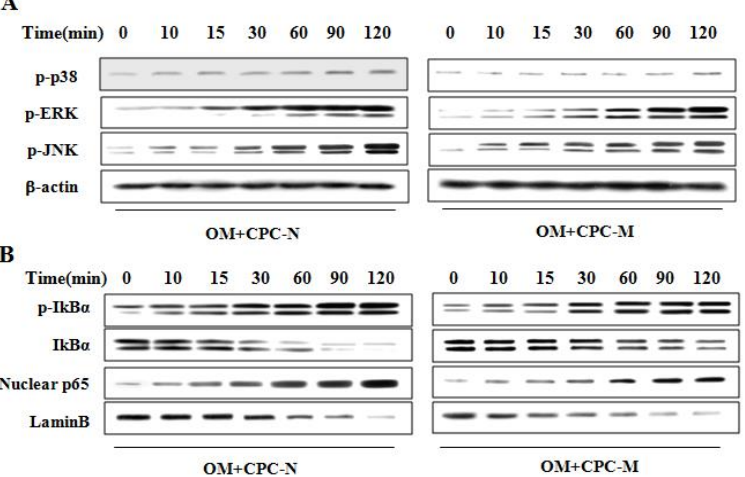

C
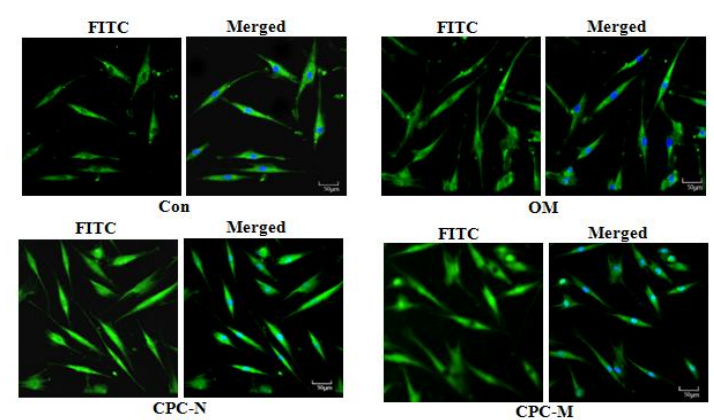

Figure 7. Effects of the nano- and micro-CPCs on the phosphorylation of MAPK (A), and the activation of the NF-KB signaling pathway in HDPSCs (B,C). The cells were cultured in CPCs with osteogenic medium (OM) for the indicated times, and the signal pathways were assessed via Western blot (A, B) and immunofluorescence staining (C). Data are representative of three independent experiments. 


\section{REFERENCES}

1 Y. Sumita, M. J. Honda, T. Ohara, S. Tsuchiya, H. Sagara, H. Kagami and M. Ueda, Biomaterials, 2006, 27, 3238-48.

2 W. H. Moolenaar, J. Biol. Chem., 1995, 270, 12949-52.

3 M. L. Couble, J. C. Farges, F. Bleicher, B. Perrat-Mabillon, M. Boudeulle and H. Magloire, Calcif. Tissue Int., 2000, 66, 129-38.

4 Y. Miyamoto, K. Ishikawa, M. Takechi, T. Toh, Y. Yoshida, M. Nagayama, M. Kon and K. Asaoka, J. Biomed. Mater. Res., 1997, 37, 457-64.

5 R. A. Perez, S.-H. Shin, C.-M. Han and H.-W. Kim, Tissue Eng. Regen. Med., 2015.

$6 \quad$ R. A. Perez, H.-W. Kim and M.-P. Ginebra, J. Tissue Eng., 2012.

7 A. M. Cherng, L. C. Chow and S. Takagi, J. Endod., 2001, 27, 613-5.

8 A. Sugawara, L. C. Chow, S. Takagi and H. Chohayeb, J. Endod., 1990, 16, 162-5.

9 H. M. Chaung, C. H. Hong, C. P. Chiang, S. K. Lin, Y. S. Kuo, W. H. Lan and C. C. Hsieh, J. Formos. Med. Assoc., 1996, 95, 545-50.

10 S.-K. Lee, S.-K. Lee, S.-I. Lee, J.-H. Park, J.-H. Jang, H.-W. Kim and E.-C. Kim, J. Endod., 2010, 36, 1537-42.

11 W.-J. Bae, S.-W. Chang, S.-I. Lee, K.-Y. Kum, K.-S. Bae and E.-C. Kim, J. Endod., 2010, 36, 1658-63.

12 B. Enkel, C. Dupas, V. Armengol, J. Akpe Adou, J. Bosco, G. Daculsi, A. Jean, O. Laboux, R. Z. LeGeros and P. Weiss, Expert Rev. Med. Devices, 2008, 5, 475-94.

13 S. V. Dorozhkin, J. Mater. Sci., 2008, 43, 3028-3057.

14 M. Espanol, R. A. Perez, E. B. Montufar, C. Marichal, A. Sacco and M. P. Ginebra, Acta Biomater., 2009, 5, 2752-62.

15 E. Engel, S. Del Valle, C. Aparicio, G. Altankov, L. Asin, J. A. Planell and M.-P. Ginebra, Tissue Eng. Part A, 2008, 14, 1341-51. 

Biomater., 2011, 97, 156-166.

17 M. Otsuka, Y. Matsuda, Y. Suwa, J. L. Fox and W. I. Higuchi, J. Biomed. Mater. Res., 1995, 29, $25-32$.

R. A. Perez, G. Altankov, E. Jorge-Herrero and M. P. Ginebra, J. Tissue Eng. Regen. Med., 2013, 7, 353-61.

M. Kitagawa, H. Ueda, S. lizuka, K. Sakamoto, H. Oka, Y. Kudo, I. Ogawa, M. Miyauchi, H. Tahara and T. Takata, Arch. Oral Biol., 2007, 52, 727-31.

21 J.-J. Kim, S.-J. Kim, Y.-S. Kim, S.-Y. Kim, S.-H. Park and E.-C. Kim, J. Endod., 2012, 38, 899906. $407-12$.

24 S.-J. Kim, K.-S. Min, H.-W. Ryu, H.-J. Lee and E.-C. Kim, J. Endod., 2010, 36, 1326-31.

25 S. Gronthos, K. Stewart, S. E. Graves, S. Hay and P. J. Simmons, J. Bone Miner. Res., 1997, 12, 1189-97.

26 J.-J. Kim, W.-J. Bae, J.-M. Kim, J.-J. Kim, E.-J. Lee, H.-W. Kim and E.-C. Kim, J. Biomater. Appl., 2014, 28, 1069-78.

27 W.-J. Bae, K.-S. Min, J.-J. Kim, J.-J. Kim, H.-W. Kim and E.-C. Kim, Dent. Mater., 2012, 28, $1271-9$.

28 R. a Perez, T.-H. Kim, M. Kim, J.-H. Jang, M.-P. Ginebra and H.-W. Kim, J. Biomed. Mater. Res. A, 2013, 101, 923-31.

29 H. Harris, Clin. Chim. Acta., 1990, 186, 133-50.

30 C. T. Hanks, D. Fang, Z. Sun, C. A. Edwards and W. T. Butler, Eur. J. Oral Sci., 1998, 106 Suppl , 260-6. 
32 J. Käpylä, J. Ivaska, R. Riikonen, P. Nykvist, O. Pentikäinen, M. Johnson and J. Heino, J. Biol. Chem., 2000, 275, 3348-54.

33 H. Xia, R. S. Nho, J. Kahm, J. Kleidon and C. A. Henke, J. Biol. Chem., 2004, 279, 33024-34.

34 M. A. Schwartz and M. H. Ginsberg, Nat. Cell Biol., 2002, 4, E65-8.

35 T. Wada, T. Nakashima, N. Hiroshi and J. M. Penninger, Trends Mol. Med., 2006, 12, 17-25.

36 H. H. Cho et al., J. Cell Physiol., 2010, 223, 168-77.

37 K. Hess, A. Ushmorov, J. Fiedler, R. E. Brenner and T. Wirth, Bone, 2009, 45, 367-76.

38 X. Feng et al., Cell Biol. Int., 2013, 37, 1267-75. 
Table 1. Reverse transcriptase-polymerase chain reaction (RT-PCR) primers and conditions.

\begin{tabular}{|c|c|c|c|c|}
\hline Genes & Primer Sequence $\left(5^{\prime}-3^{\prime}\right)$ & $\begin{array}{l}\text { Annealing } \\
\text { Temp } \\
\left({ }^{\circ} \mathrm{C}\right)\end{array}$ & $\begin{array}{l}\text { Cycle } \\
\text { Number }\end{array}$ & $\begin{array}{l}\text { Product } \\
\text { Size (bp) }\end{array}$ \\
\hline DSPP & $\begin{array}{l}\text { F : 5'- AGAAGGACCTGGCCAAAAAT-3' } \\
\text { R : 5'- TCTCCTCGGCTACTGCTGTT-3' }\end{array}$ & 60 & 35 & 280 \\
\hline DMP-1 & $\begin{array}{l}\text { F: 5'- GATCAGCATCCTGCTCATGTT-3' } \\
\text { R: 5'- AGCCAAATGACCCTTCCATTC-3' }\end{array}$ & 55 & 35 & 125 \\
\hline & F: 5'-GTGCAGCCTTTGTGTCCAAGCAGGA- & & & \\
\hline $\mathrm{OCN}$ & $\begin{array}{l}\text { 3' } \\
\text { R: 5'-CCGTAGAAGCGCCGATAGGCC-3' }\end{array}$ & 60 & 30 & 244 \\
\hline OPN & $\begin{array}{l}\text { F: 5'- CCCACAGACCCTTCCAAGTA-3' } \\
\text { R: 5'- GGGGACAACTGGAGTGAAAA-3' }\end{array}$ & 60 & 35 & 196 \\
\hline BSP & $\begin{array}{l}\text { F: 5'- TGGAGATGACAGTTCAGAAG -3' } \\
\text { R: 5'- GTACTGGTGCCGTTTAtGC -3' }\end{array}$ & 52 & 35 & 333 \\
\hline Integrina1 & $\begin{array}{l}\text { F: 5'- TGCTGCTGGCTCCTCACTGTTGT -3' } \\
\text { R: 5'- TAGTCTGGCGGCCACСTCTCTG -3' }\end{array}$ & 61 & 32 & 135 \\
\hline Integrina2 & $\begin{array}{l}\text { F: 5'- TTTCCCTGCTCTCACCGGGC -3' } \\
\text { R: 5'- ACCGGGGGACCGTAGTTGCG -3' }\end{array}$ & 61 & 32 & 412 \\
\hline Integrin $\beta 1$ & $\begin{array}{l}\text { F: 5'-GACGCCGCGCGGAAAAGATG-3' } \\
\text { R: 5'-ACCACCCACAATTTGGCCCTGC-3' }\end{array}$ & 61 & 35 & 159 \\
\hline$\beta$-actin & $\begin{array}{l}\text { F: 5'- CATGGATGATGATATCGCCGCG-3' } \\
\text { R: 5'- ACATGATCTGGGTCATCTTCTCG-3' }\end{array}$ & 60 & 35 & 371 \\
\hline
\end{tabular}


Table 2. Characterization of the 'initial' particles used for the micro- and nano-sized CPCs.

\begin{tabular}{|l|l|l|}
\hline & for micro-CPC & for nano-CPC \\
\hline Initial particle size $(\mu \mathrm{m})$ & $5.841 \pm 0.572$ & $2.444 \pm 0.048$ \\
\hline Specific surface area of initial particles $\left(\mathrm{m}^{2} / \mathrm{g}\right)$ & $1.228 \pm 0.008$ & $3.053 \pm 0.019$ \\
\hline
\end{tabular}

